\title{
MEIA DUZIA DE CASOS PARA-CLINICOS
}

Para os moços que acabam de diplomar-se, e vão tentar os seus primeiros passos na profissão, a clinica se apresenta com a rosea perspectiva das manhãs harmoniosas, todas cheias de esperanças e futuros triumphos.

Aos clinicos em pleno exercicio, a profissão se mostra, em gerai. cheia de espinhos e desillusões, na desegualdade permanente da lucta contra a molestia insidiosa, ou a morte irremediavel, na caça porfiada ao diagnostico obscuro e inseguro, ou na ancia do prognostico certo e positivo.

Mas, com o correr dos annos, depois de 20 ou mais de exercicio, a profissão começa a ter as suas doçuras, assentes sobretudo no relembrar de casos interessantes ou extranhos que vão pontilhando a vida e que já vae sendo agradavel recordar.

E' o que faço agora.

Não é pois um artigo de sciencia o que se vae lêr, antes um rosario de recordações medicas, que nem sempre terão o interesse da novidadt ou da raridade, mas sempre o sabor dos bons dias já passados.

$\mathrm{E}$ quem se pode furtar a esse doce prazer de recordar?

Ponham os velhos clinicos a mão na consciencia, e busquem lembrarse da emoção do primeiro attestado de obito...

O meu primeiro vae já para 25 annos; foi de uma creança, victimada por traiçoeira gastro-enterite, que visitei uma só vez; mas a emoção foi tal, que datei e assignei o fatal documento. sobre uma estampilha federal!

Em compensação quanta alegria, quanto prazer nos casos felizes.

Tenho sempre em uma das gavetas da minha meza de trabalho a fotographia de um rude tiabalhador a quem extirpei um colossai lipoma, que lhe impossibilitava o trabalho e lhe atormentava a vida. E ao rever os traços já semi-apagados d'essa velha fotographia me recordo sempre com um doce sorriso de compaixão e ironia da sua singela historia!

Casara, por amor, com uma guapa rapariga do bairro, e celebrára a bôda em uma sexta-feira.

Como o casamento era todo de inclinação a bôda fôra alegre e farła.

Alguem, no meio d'ella, reclamara do peccado de darem os noiyos uma tal festa e uma refeição toda cheia de carne, em dia tão improprio, em dia de abstinencia.

Elle, o noivo, que n'esse dia só via e só sentia a felicidade do seu! noivado ergueu-se ousado e blasphemou :

- Não faz ma!; comam e beham que o culpado sou eu. Se ha peccado, cáia todo na minha cacunda!

E cahiu mesmo.

Tempos depois do feliz dia, não muitos começou a crescer-lhe nas costas um pequeno volume de carne, que foi crescendo e crescendo atté ao tamanho que o snr. vê, dizia o velho caboclo, levantando a camisà e mostrando um enorme lipoma, assente sobre a homoplata esquerda por um largo pediculo e descendo pelas costas em forma de pera ate abaixo das nadegas, a ponto de não poder sentar-se em cadeira por năo ter accomodação o tumor.

- Eu sei que foi castigo de Deus, que eu offendi com as minhas palavras. mas creio que já soffri bastante. e Deus ha de se amercear 
le mim e permittir que o snr. dr. me tire esta lastima de furungo que não me deixa mais trabalhar.

Com effeito, Deus permittiu, e o tumor foi extirpado. Era um simples lipoma pezando 18 kilos e com uma vasta inserção sobre a homoplata esquerda, de uns dez por seis ou oito centimetros. $O$ tempo difficil da intervenção foi apenas o inicial, isto é, o da apprehensão do tumor

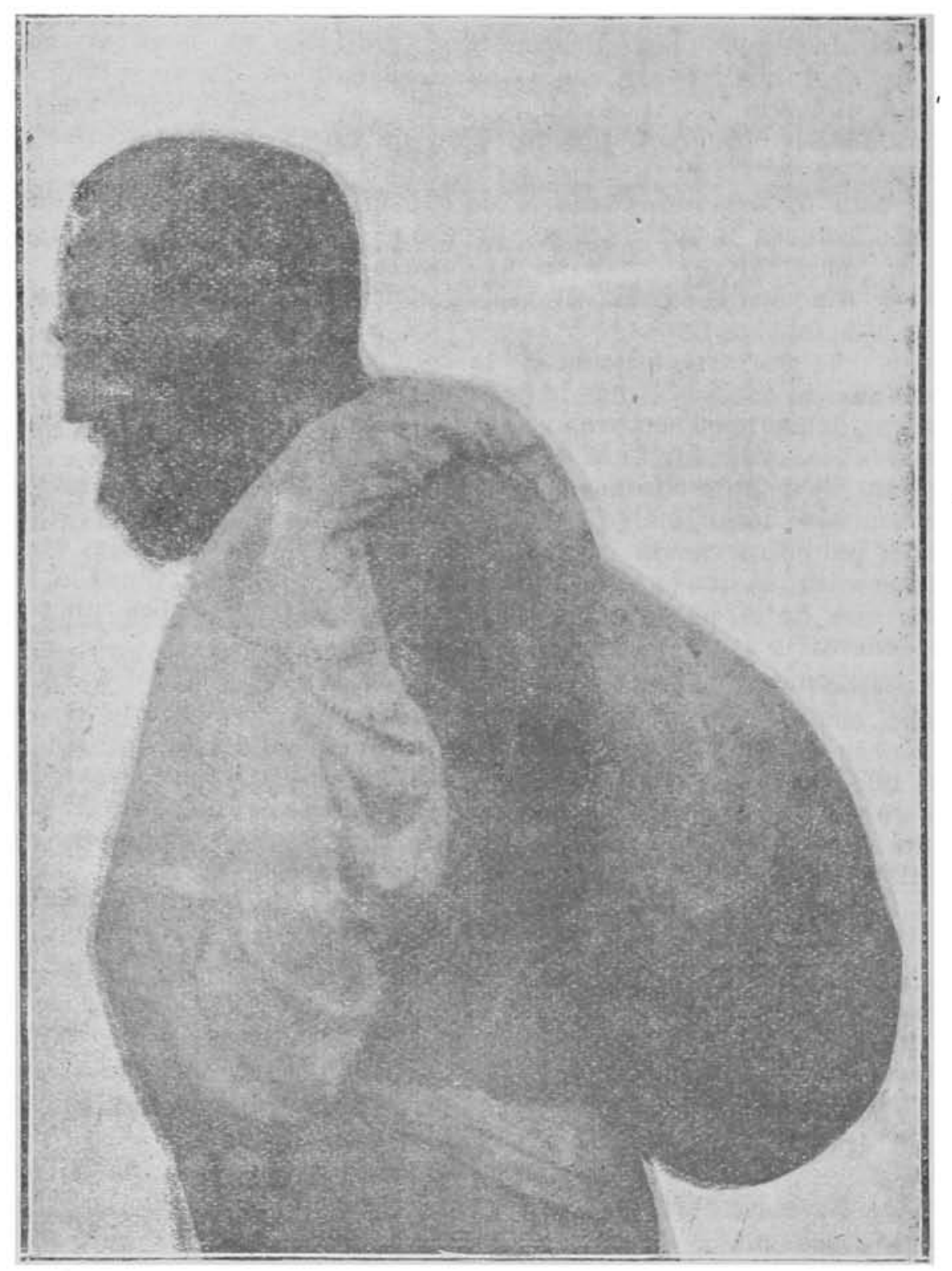

Lim lypoma gigantesco que alcançou o peso de 18 kilos. Conhece o leitor algum maior?...

que era impossivel ser levantado pelo cirurgião e mesmo por um ajudante; foi necessario fixar uma roldana no tecto da sala de operação e suspender por meio d'ella o tumor com uma corda.

Cicatrisação por primeira intensão. 
Ao levantar-se já curado, o velho caboclo não se equilibrava; pendia desastradamente para a frente. Faltava-lhe o contra peso do tumor que o acompanhara por vinte annos e ao qual já se adaptara.

A philosophia bonacheirona e resignada d'esse doente que durante tão longos annos supportou um merecido castigo, me recorda sempre, um outro caso clinico occorrido em um dos mais atrazados recantos do Norte Paulista.

Certa noite, chamado a assistir uma parturiente a quem as comadres do bairro não conseguiam alliviar, necessitei fazer uma aplicação de forceps para vencer a ultima difficuldade d'aquelle laborioso partọ.

Mas a casa era tão pequena, tão acanhado o quarto e de tal sorte collocada a tarimba, unica da casa, onde se accomodava a parturiente, que se tornou necessario fazer derrubar a parede que separava o quarto da saleta de entrada.

Parede de pau a pique, ligeiramente barreada a sopapo, facilmente foi demolida.

Occupou-se do serviço o proprio marido da doente, dono da casa, que após tal serviço sumiu, durante todo o tempo da intervenção e consequente extracção.

Findo o trabalho, recomposta a mãe, lavada a creança, sahi ao terreiro em busca de agua para lavar as mãos e o forceps. Amanhecia.

Ao humbral exterior da porta encontrava-se o caboclo, com a cabeça erguida, olhos vagos no longe, como que scismando.

- Prompto camarada!

Está tudo feito; a mulher alliviada e você com mais um filho.

Como não respondesse, insisti:

- Mas em que está você per:sando?

Moveu-se o rosto do caboclo, e um sorriso alegre e convencido the desceu por todo elle e, em voz baixa e cautelosa, murmurou:

- Estou pensando em ter sido muito bom que fosse Deus quem fez - mundo. Se fosse Nossa Senhora, certamente empurrava todos estes trabalhos para cima de nós!

$\mathbf{E}$ apontava com o beiço para a tarimba onde a mulher gemia ainda - o filho começava a chorar.

Paralella, bem paralella ao egoismo epicureano d'esse caboclo que dos soffrimentos da mulher só deduziu a conclusão da sorte de ter sido Deus masculino, é esta outra historia de uma preta cosinheira a quem tive, certa occasião, de operar um grosso fibroma uterino de mais de 20 kilos de peso e que lhe enchia, literalmente, um ventre enorme e proeminente.

Recolhida ao hospital, laparatomisada e feita a hysteredomia total, foi para todos um espanto o tamanho e volume do tumor que era, realmente, um fibroma gigante. De todos o mais espantado e surprezo era o marido da doente, preto jornaleiro, pernostico e cachaceiro incorrigivel.

O seu espanto, sua surpreza foram taes que só na cachaça encontrou a habitual consolação. Na cachaça procurou tambem a satisfação de vêr a mulher livre de uma tal peste. E tanto se acalmou do espanto, tanto combateu a surpreza e de tal forma festejou a alegria da feliz operação, que se embriagou terrivelmente, alta noite, e cahiu da ponte sobre o F'arahyba. morrendo afngado.

No hospital houve o mais severo cuidado em ocultar da operada o desastre do marido.

E só passados 12 dias, quando já restabelecida, de pé e em vespera de se retirar com alta, lhe contei, em proprio, o succedido, adoçando a noticia da melhor forma possivel. Quando soube tudo, que o marido 
havia se embriagado por causa e em gaudio da feliz operação e em consequencia da bebedeira, cahido ao rio e se afogado, estando já agora enterrado, fazia dias, a preta ergue-se, caminha para mim de braços estendidos, abraça-me fortemente e, em vez da effusão de lagrimas, ou lamentos que esperava, diz-me, simplesmente, commovida e satisfeita:

- Obrigada dr. Com uma só operação livrou-me de duas pestes: o tumor e o marido!

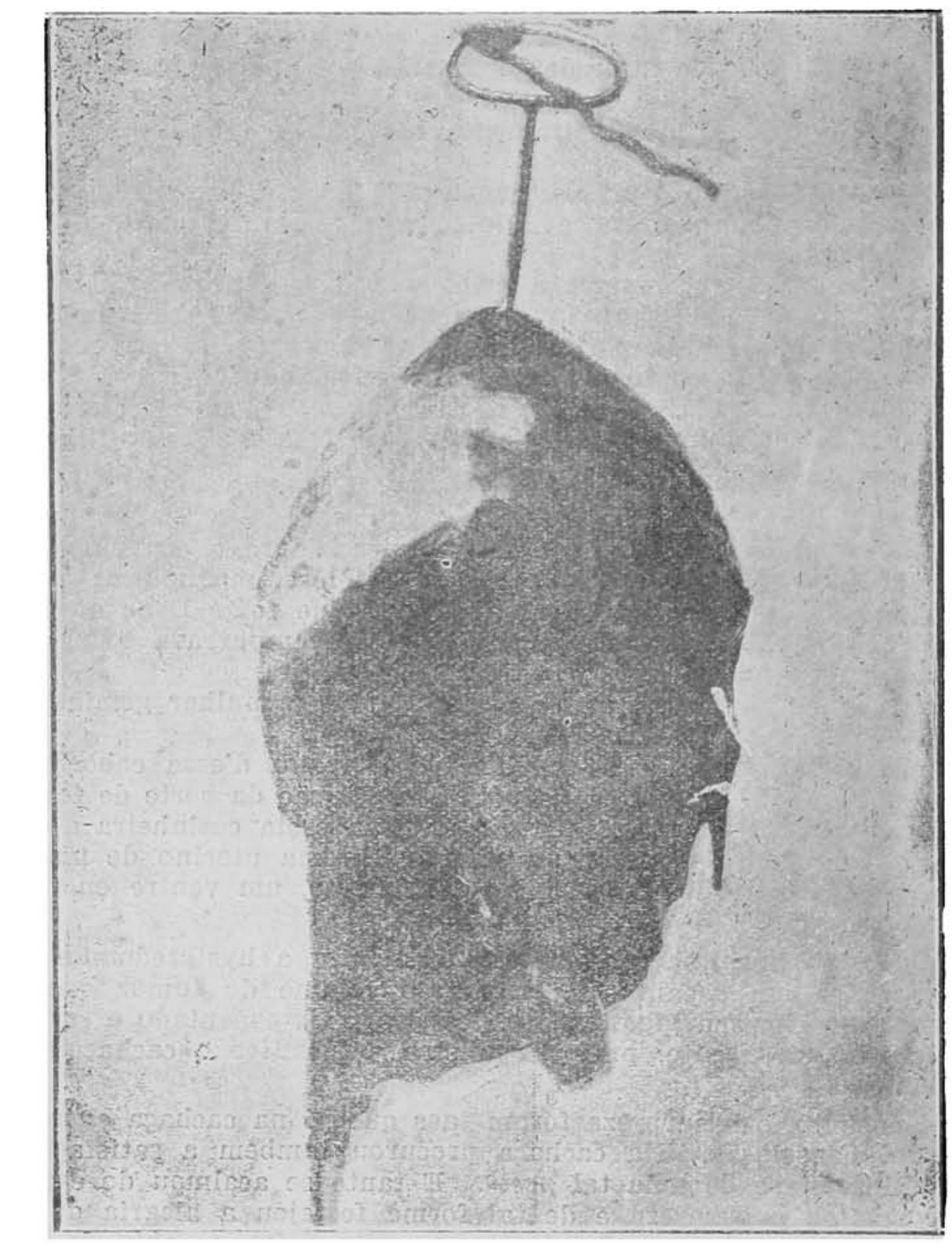

Im fibroma uterino de 20 k.los. Para melhor julgar-lhe o volume, ccmpare o, o leitor, á mosca que se vê, em cima, á direita, não longe da haste metallica...

Era a vingança da Eva escravisada pela pernosticidade e pelo vicio do marido, contra o egoismo boçal do Adão, pae da "creança" tirada a forceps. 
E assim vão, em geral os sentimentos dos nossos patricios perdidos, sem instrucção nem educação, por esses sertões a fóra...

Mas, por vezes tambem a sciencia nas suas mais modernisadas manifestações nos prega peças, não menos para rir, do que os ditos e gestos dos nossos caipiras.

Fui ha tempos consultado por um rapaz, ainda moço, que se queixava de dores renaes e perturbações urinarias varias.

Indagado, fez-me saber que havia tres annos consultara já por causa semelhante e que lhe fôra feito o diagnostico de calculos renaes. Possuia mesmo uma radiographia, feita n'essa occasião, analyses de urinas e qưatro ou cinco pequenas pedras que urinara, sendo que a maior d'ellas ficou engastada no meato, de onde foi necessario retiral-a por meios cirurgicos. Não quizera porém submetter-se a uma intervenção aconselhada, sobretudo por que melhorara.

Agora, novamente doente, estava disposto a ser operado.

Aconselhei nova radiographia, nova analyse de urina, visto as que me apresentava datarem já de dez annos.

Dias após, volta ao escriptorio trazendo as duas radiographias, e as duas analyses de urina, as velhas e as novas.

As radiographias, poderiam sobrepôr-se uma á outra. Em ambas a sombra do rim direito se projectava augmentado de volume, e no seu Interior mostrava dois corpos opacos: um em forma de feijão, oụtro coraliforme. As duas analyses de urina eram quasi a copia uma da outra: - alguma albumina, pús, cellulas do bacinete e de bexiga.

Calculos de bacinete, impunha-se como diagnostico.

Proposta e acceita, a intervenção é praticada depois de todos os exames preliminares que demonstraram são o rim esquerdo, e doente e quasi sem funcção o direito.

Aberta porém a loja renal, aberto o rim, nenhum calculo!

Procura-se no bacinete, na primeira porção da urether, nos calices. nada!

O aspecto do rim porém impõe a sua ablação, pois é marmorisado, com pequenns abcessos e pontos de suffusão sanguinea.

Nephrectomia.

Terminada a operação retalha-se o rim por todos os meridianos á busca de calculos que não existem.

o laboratorio demonstra dias depois que se trata de um rim tuberculoso.

Intrigado com o caso, mando o doente a novo exame radiologico, em resultado do qual recebo uma chapa absolutamente igual ás que já possuia e podendo a ellas se sobrepôr, com duas manchas opacas: uma em forma de feijão e outra caraliforme. O relatorio que acompanhava a radiographia dizia apenas - calculos no rim direito.

No rim direito, aquelle que eu havia retirado e conservava, sem um pedaço que fôra ao laboratorio, dentro de um bocal, no meu consultorio!

Potente apparelho, grande meio diagnostico! Fol realmente bom ter sido Deus quem fez o mundo, como dizia o caboclo meu amigo..

Imaginem se houvesse sido Röentgen e tivesse dado aos raios solares a qualidade de penetraçito dos seus raios, quantas coisas maravilhosas e incriveis veriamos, diariamente, nos orgãos que temos e nos.! que já não temos.

E nas consciencias?

Foi, foi realmente muito bom, ter sido Deus quem fez o mundo.

GAMA RODRIGUES. 